\title{
Effects of gestation and birth weight on the growth and development of very low birthweight small for gestational age infants: a matched group comparison
}

\author{
Tina Gutbrod, Dieter Wolke, Brigitte Soehne, Barbara Ohrt, Klaus Riegel
}

\begin{abstract}
Aims-To investigate the effects of small for gestational age (SGA) in very low birthweight (VLBW) infants on growth and development until the fifth year of life. Methods-VLBW (< $1500 \mathrm{~g})$ infants, selected from a prospective study, were classified as SGA $(n=115)$ on the basis of birth weight below the 10th percentile for gestational age and were compared with two groups of appropriate for gestational age (AGA) infants matched according to birth weight (AGA-BW; $n=115$ ) or gestation at birth (AGA-GA; $n=115$ ). Prenatal, perinatal, and postnatal risk factors were recorded, and duration and intensity of treatment were computed from daily assessments. Body weight, length, and head circumference were measured at birth, five and 20 months (corrected for prematurity), and at 56 months. General development was assessed at five and 20 months with the Griffiths scale of babies abilities, and cognitive development at 56 months with the Columbia mental maturity scales, a vocabulary (AWST) and language comprehension test (LSVTA).
\end{abstract}

Results-Significant group differences were found in complications (pregnancy, birth, and neonatal), parity, and multiple birth rate. The AGA-GA group showed most satisfactory growth up to 56 months, with both the AGA-BW and SGA groups lagging behind. The AGA-GA group also scored significantly more highly on all developmental and cognitive tests than the other groups. Developmental test results were similar for the SGA and AGA-BW groups at five and 20 months, but AGA-BW infants (lowest gestation) had lower scores on performance intelligence quotient and language comprehension at 56 months than the SGA group. When prenatal and neonatal complications, parity, and multiple birth were accounted for, group differences in growth remained, but differences in cognitive outcome disappeared after five months.

Conclusions-Being underweight and with a short gestation (SGA and VLBW) leads to poor weight gain and head growth in infancy but does not result in poorer growth than in infants of the same birth weight but shorter gestation (AGA-BW) in the long term. SGA is related to early developmental delay and later language problems; however, neonatal complications may have a larger detrimental effect on long term cognitive development of VLBW infants than whether they are born SGA or AGA.

(Arch Dis Child Fetal Neonatal Ed 2000;82:F208-F214)

Keywords: small for gestational age; very low birth weight; growth; development; cognitive development

Very low birthweight infants (VLBW) are at increased risk of poor long term growth ${ }^{1-3}$ and cognitive and language deficits. ${ }^{4}$ Those VLBW infants born small for gestational age (SGA) have been suggested to be at double jeopardy because of their shortened gestational period as well as intrauterine growth retardation. ${ }^{56} \mathrm{~A}$ higher incidence of prenatal and perinatal complications, as well as lower cognitive scores and poorer growth during the first years of life, has been reported in SGA infants compared with those with an appropriate weight for gestational age (AGA). ${ }^{7-10}$

However, the relative significance of growth retardation, low birth weight, and gestation on the development of very preterm infants remains controversial. Spinillo et $a l^{11}$ found the significance of lower than expected birth weight as a predictor of neonatal outcome to be lower than that of gestational age. In contrast, Hutton et $a l^{5}$ found birthweight ratio but not gestation to predict cognitive ability at 8-9 years of age.

Methodological factors and sample characteristics have been speculated to account for differences in reported outcomes, such as the definition of SGA, size of sample, range of gestational ages and birth weights in the sample, and the duration of follow up. ${ }^{12}$ In addition, AGA comparison groups often differed in either birth weight or gestation, therefore it was unclear whether the neurological and cognitive impairment of the SGA group was due to shorter gestation or impaired prenatal growth.

Recently two studies compared the growth and development of low birthweight SGA infants with those of both gestational age matched and birthweight matched low birthweight AGA infants. McCarton et $a l^{12}$ compared a large sample $(n=129)$ of low birthweight $(<2000 \mathrm{~g})$ SGA (<3rd percentile) infants with AGA infants grouped either by birth weight or gestation. Poorer cognitive scores and neurological deficits up to 6 years of age were more likely in SGA infants than in 
AGA infants of comparable gestation. There were no differences in neurological or cognitive outcomes at any age when grouped by birth weight. Sung et $a l^{13}$ compared a smaller sample $(\mathrm{n}=27)$ of VLBW $(<1500 \mathrm{~g})$ SGA $(<10$ th percentile) infants with two groups of VLBW AGA infants matched for either gestation or birth weight up to the age of 3 . As in the previous study, SGA infants scored lower on developmental tests than the gestation matched AGA group, but had similar scores to the AGA infants matched according to birth weight. However, at 3 years of age, SGA infants had lower weight and height than both comparison groups. Sung et $a l^{13}$ conclude that intrauterine growth retardation in VLBW infants has a significant long term impact on growth, but extreme immaturity (short gestation) has significant effects on neurodevelopmental outcome that surpass the effects of intrauterine growth retardation.

About half of all SGA infants are born to mothers with obstetric complications, and as many as $65 \%$ of SGA infants, compared with AGA infants, experience perinatal problems. ${ }^{14}$ Uncertainty remains about whether complications during pregnancy, at birth, and during the neonatal period, as well as parental smoking during pregnancy, parity, and multiple birth may account for the long term developmental outcome in VLBW SGA infants.

The present study investigated the influence of birth weight and gestation on growth and cognitive development of a large group of VLBW SGA infants until the 5 th year of life by adopting the design of Sung et $a l^{13}$ and matching two distinct groups of AGA infants according to gestation and birth weight. It was further determined whether any effects of gestation or birth weight remained on growth and general and cognitive development after controlling for prenatal and neonatal complications, parity, and multiple birth.

\section{Methods}

SUBJECTS

Children were selected from the subject pool of the Bavarian longitudinal study ( $\mathrm{n}=7505)$, a prospective population study of all infants born and admitted to one of 16 children's hospitals in South Bavaria, Germany in the first 10 days of life during the period 1 February 1985 to 31 March 1986. ${ }^{341516}$ The selection criteria were: participation in all assessments at five, 20, and 56 months; absence of blindness, deafness, or severe cardiopulmonary or other major congenital anomalies, chromosomal defects, or intrauterine infections.

The SGA group consisted of 115 VLBW infants with a birth weight of $<1500 \mathrm{~g}$ who were identified as having birth weights below the 10 th percentile for gestational age on sex specific standards. Gestational age was determined from maternal dates of the last menstrual period, serial ultrasound examination during pregnancy, and Dubowitz examinations. ${ }^{17}$ When gestational age estimates from these methods differed by less than two weeks, maternal dates were used; when the difference between the three methods was greater than two weeks-for example, uncertain datesthen Dubowitz examination results alone were used to determine gestational age.

After the SGA infants had been identified, they were matched with two comparison groups of AGA infants: AGA-GA, 115 infants born AGA were matched with the SGA group according to gestation at birth (within exact day); AGA-BW, 115 infants born AGA, who were not included in the AGA-GA group, were matched with the SGA group according to birth weight $( \pm 100 \mathrm{~g})$. As a result, the two AGA groups were distinct in membershipthat is, none of the children belonged to both groups. Sex was balanced accordingly (58 boys, 57 girls in each group).

A cohort specific normative sample ( $\mathrm{n}=$ 432) of infants representative of Bavarian children born in $1985^{3}{ }^{18}$ was concurrently studied to standardise sex specific norms of anthropometric (weight, length, and head circumference) and cognitive (intelligence quotient (IQ) and language comprehension) assessments at five, 20 and 56 months.

INSTRUMENTS AND PROCEDURES

Parents in the Bavarian longitudinal study were approached within 48 hours of the infant's admission to hospital; the study aims were explained, and the parents were asked to give written consent to participate.

Prenatal data were coded from the medical histories in the obstetric units, while perinatal and neonatal data were collected prospectively. The information was summarised into three scales of complications during pregnancy (14 complications), birth (13 complications), and the neonatal period (21 complications). Presence of a complication was scored as 1 and absence as 0 ; the scores were then totalled separately for pregnancy, birth, and neonatal period as previously described. ${ }^{3} 15161819$ Information on parity and multiple birth was obtained from hospital records.

Daily assessments of care level, respiratory support, feeding dependency, and neurological status such as mobility, muscle tone, and neurological excitability were carried out from day one after birth. Each of the six variables were scored daily on four point rating scales $(0-3)$ by the method of Casaer and Eggermont. ${ }^{20}$ The duration of intensive neonatal treatment index (DINTI) was computed as the number of days until the infant reached a stable clinical state (total daily scores $<3$ for three consecutive days), and the intensity of neonatal treatment index (INTI) was computed as the mean of daily ratings during the first 10 days of life or until a stable clinical state was reached, depending on which occurred sooner. ${ }^{15} 16$ Socioeconomic data and information on smoking (pregnancy, current) were obtained by standard interviews with the infants' parents in the first 10 days of life and at each follow up visit. Socioeconomic status was computed as a weighted composite score of maternal highest educational qualification, paternal highest educational qualification, and occupation of the head of the family. ${ }^{15}$ 
Body weight, length, and head circumference were measured at birth, five and 20 months corrected for prematurity, and at 56 months by specially trained research nurses during follow up visits in the assessment centres (hospitals) using a predefined protocol: weighing on standard scales in underwear only; standard application for head circumference measurement. At five and 20 months of age corrected for prematurity, general development was assessed with the German version of the Griffiths scale of babies abilities ${ }^{22}$ and expressed as developmental quotients (DQs). At 56 months, children were administered the following tests: $(a)$ the Columbia mental maturity scales (CMM), ${ }^{23}{ }^{24}$ an assessment of performance IQ; (b) the AWST, ${ }^{25}$ a vocabulary assessment similar to the Peabody picture vocabulary test used to determine verbal intelligence; $(c)$ the LSVTA subscale, ${ }^{26}$ an assessment of comprehension (the child is given a set of standard materials and asked to perform sequences of actions given verbally by the examiner). The CMM, AWST, and LSVTA were standardised as 100 (15) (SD) according to the normative sample. ${ }^{18}$

All cognitive assessments were carried out by specially employed paediatricians and research nurses in specially equipped assessment rooms attached to the childrens' hospitals in South Bavaria. All investigators were trained in the assessment procedures and were unaware of the infants' neonatal course and previous test results.

Ethical approval was obtained from the University of Munich Children's Hospital, and the Landesärztekammer Bayern (Health council of Bavaria) was fully informed.

STATISTICAL ANALYSIS

Data were analysed by computer using the SPSS statistical package. Group differences in anthropometric and DQ/IQ scores were analysed using one factorial analysis of variance. The effects of prenatal and neonatal complica- tions, parity, and multiple birth on group differences in anthropometric and $\mathrm{DQ} / \mathrm{IQ}$ scores were investigated using analysis of covariance. $\chi^{2}$ analysis determined overall group differences in cognitive impairment. Follow up tests included a priori contrasts and comparisons for categorical data.

\section{Results}

NEONATAL CHARACTERISTICS

Table 1 shows that group matching according to either birth weight or gestation achieved comparable groups. Those matched according to birth weight (AGA-BW $v$ SGA) differed significantly (by more than three weeks) in gestational age, duration of care, and intensity of care, but were very similar in head circumference and length at birth. The AGA-BW group had higher complication scores neonatally, but did not differ in complication scores during pregnancy or at birth. They took longer to reach medical stability (DINTI), had higher treatment intensity scores (INTI), longer duration of ventilation and parenteral nutrition, but did not require more time until discharge from hospital than the SGA group. In addition, the AGA-BW group contained fewer firstborns and more multiple births than either of the other groups.

The groups matched according to gestation (AGA-GA $v$ SGA) differed in birth weight, head circumference, length at birth, duration of care, and intensity of care. The AGA-GA group had fewer risk factors during pregnancy, at birth, and during the neonatal period, and took significantly less time to reach medical stability (DINTI), had lower treatment intensity scores (INTI), shorter duration of ventilation and parenteral nutrition, and required less time until discharge from hospital than the SGA infants. In addition, the AGA-GA group contained fewer firstborns than the SGA group.

There were no significant differences among the three groups in socioeconomic status,

Table 1 Characteristics of very low birthweight infants classified as small for gestational age (SGA) or appropriate weight for gestational age matched according to birth weight $(A G A-B W)$ or gestation $(A G A-G A)$

\begin{tabular}{lccc}
\hline & $A G A-B W$ & $S G A$ & $A G A-G A$ \\
\hline Obstetric/neonatal & & & \\
Birth weight (g) & $1237(18)$ & $1232(18)$ & $1982(43)^{\star \star \star}$ \\
Gestation at birth (weeks) & $29.2(0.16)^{\star \star \star}$ & $32.4(0.22)$ & $32.4(0.22)$ \\
Head circumference at birth (cm) & $27.1(0.21)$ & $27.6(0.18)$ & $30.6(0.19)^{\star \star \star}$ \\
Length at birth (cm) & $38.6(0.26)$ & $38.7(0.29)$ & $44.1(0.31)^{\star \star \star}$ \\
Complication score during pregnancy & $2.3(0.11)$ & $2.6(0.12)$ & $2.0(0.12)^{\star \star}$ \\
Complication score at birth & $4.3(0.12)$ & $5.2(0.12)$ & $3.8(0.15)^{\star}$ \\
Complication score, neonatal & $9.8(0.24)^{\star \star}$ & $8.7(0.24)$ & $6.8(0.28)^{\star \star \star}$ \\
Duration of treatment index (days) & $68.0(8.7)^{\star}$ & $48.4(2.7)$ & $29.0(3.0)^{\star \star \star}$ \\
Intensity of neonatal treatment index (days) & $12.6(0.36)^{\star \star \star}$ & $10.2(0.37)$ & $8.6(0.37)^{\star \star}$ \\
Duration of ventilation (IPPV) (days) & $17.5(1.7)^{\star \star}$ & $10.9(1.7)$ & $5.5(1.7)^{\star}$ \\
Duration of sole parenteral nutrition (days) & $5.8(0.63)^{\star}$ & $3.9(0.63)$ & $2.1(0.63)^{\star}$ \\
Days until discharge (days) & $80.2(2.6)$ & $73.1(2.9)$ & $45.6(3.1)^{\star \star \star}$ \\
Demographic & & & 49 \\
Sex (\% female) & 49 & 49 & 18 \\
Socioeconomic status (\%) & 21 & 18 & 47 \\
High & 40 & 40 & 35 \\
Middle & 39 & 42 & $28.8(0.49)$ \\
Low & $29.2(0.50)$ & $28.1(0.46)$ & $48^{\star}$ \\
Maternal age at birth (years) & $49^{\star}$ & 69 & 27 \\
Parity (\% firstborn) & $35^{\star}$ & 16 & 8 \\
Multiple birth (\% multiple birth) & 12 & 14 & 11 \\
Maternal education (\% A levels/University) & 5 & & \\
Single (\%) & & &
\end{tabular}

Where appropriate, values are expressed as mean $(\mathrm{SEM})(\mathrm{n}=115)$.

${ }^{\star} \mathrm{p}<0.05,{ }^{\star \star} \mathrm{p}<0.01,{ }^{\star \star \star} \mathrm{p}<0.001 v$ SGA. 


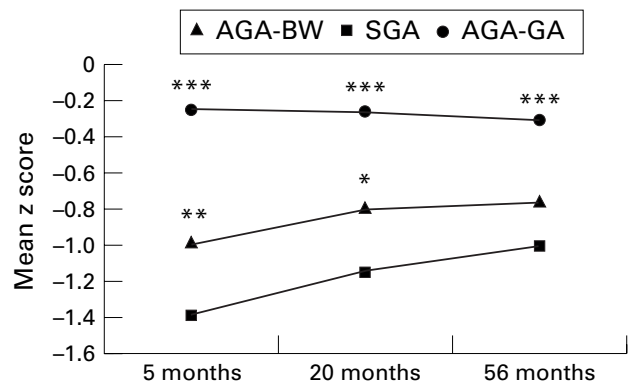

Figure 1 Group differences in weight at five months, 20 months, and 56 months. SGA, group of small for gestational age infants; $A G A-B W$, group of appropriate for gestational age infants matched to the SGA group according to birth weight; $A G A-G A$, group of appropriate for gestational age infants matched to the $S G A$ group according to gestational age. ${ }^{\star} p<0.05,{ }^{\star \star} p<0.01$, $\star \star \star p<0.001$ v SGA.

marital status, age, or education of the mother (table 1).

COMPLICATIONS DURING PREGNANCY, AT BIRTH, AND NEONATALLY

Table 2 shows a comparison of groups with regard to individual complications that were included in the complication scores and occurred with sufficient frequency during pregnancy, birth and neonatally. No group differences in prevalence of maternal or paternal smoking were found. During pregnancy, mothers of SGA infants had a higher incidence of pre-eclampsia than the mothers in the two AGA groups. SGA infants were more often born by caesarian section than AGA infants. In the neonatal period, all three groups differed in the incidence of complications (table 2).

GROWTH

Significant differences between the three groups in body weight, length, and head circumference remained at five, 20, and 56 months (figs 1-3).

Table 2 Specific complications (pregnancy, birth, and neonatal) of very low birthweight infants classified as small for gestational age (SGA) or appropriate weight for gestational age matched according to birth weight ( $A G A-B W)$ or gestation (AGA-GA) (percentages)

\begin{tabular}{llll}
\hline & $A G A-B W$ & $S G A$ & $A G A-G A$ \\
\hline During pregnancy & & & \\
Maternal smoking (\% smoking > 1/day) & 26.6 & 20.4 & 18.2 \\
$\quad$ If yes, cigarettes/day & $6.9(0.66)$ & $11.4(1.4)$ & $9.4(1.3)$ \\
Paternal smoking (\% smoking > 1/day) & 37.6 & 43.9 & 42.9 \\
$\quad$ If yes, cigarettes/day & $17.8(1.2)$ & $19.3(1.4)$ & $17.1(1.3)$ \\
Pre-eclampsia & $40.2^{\star}$ & 26.0 & $50.0^{\star \star \star}$ \\
Premature labour & 66.4 & 55.8 & 55.8 \\
Illness/accident during pregnancy & 27.2 & 24.3 & 25.2 \\
At birth & & & \\
Amnion infection & 31.3 & 26.1 & 20.0 \\
Anaesthesia & 11.2 & 10.6 & 18.3 \\
Caesarian section & $54.2^{\star \star}$ & 75.0 & $51.9^{\star \star \star}$ \\
Placenta praevia & 7.0 & 3.5 & 8.7 \\
Neonatal & & & \\
Intubation & $71.0^{\star \star \star}$ & 44.2 & $24.0^{\star \star}$ \\
Apgar 1 min < 9 or 5 min < 10 & $93.5^{\star \star \star}$ & 76.9 & 71.2 \\
Outborn & 61.7 & 49.6 & $62.6^{\star}$ \\
Body temperature ( $\leqslant 36^{\circ} \mathrm{C}$ ) & 38.3 & 43.5 & $19.1^{\star \star \star}$ \\
Apnoea, bradycardia & $84.3^{\star \star \star}$ & 60.9 & $43.5^{\star \star}$ \\
Hyperbilirubinaemia & 16.1 & 22.7 & $51.0^{\star \star \star}$ \\
Severe anaemia & 67.8 & 6.0 & $31.3^{\star \star \star}$ \\
Sepsis (suspicion) & 49.6 & 49.6 & $36.5^{\star}$ \\
Poor weight gain (< 10th percentile after 10th day) & $59.1^{\star \star \star}$ & 89.6 & $34.8^{\star \star \star}$ \\
Surgery & 25.2 & 17.4 & $7.0^{\star}$ \\
Fits & $20.0^{\star}$ & 8.7 & 7.8 \\
Intraventricular haemorrhage (grade III/IV) & 11.3 & 5.2 & 17.4 \\
\hline
\end{tabular}

Where appropriate, values are expressed as mean (SEM) $(n=115)$. All values are percentage scores and represent within group incidence of complications. ${ }^{\star} \mathrm{p}<0.05,{ }^{\star \star} \mathrm{p}<0.01$, $\star \star \star \mathrm{p}<0.001$ v SGA.

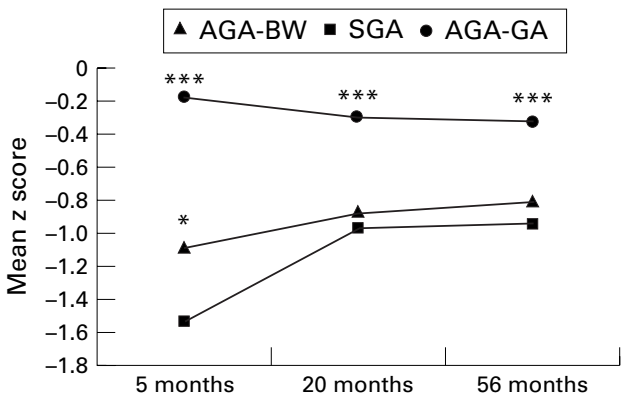

Figure 2 Group differences in length at five months, 20 months, and 56 months. $S G A$, group of small for gestational age infants; $A G A-B W$, group of appropriate for gestational age infants matched to the $S G A$ group according to birth weight; $A G A-G A$, group of appropriate for gestational age infants matched to the $S G A$ group according to gestational age. ${ }^{\star} p<0.05,{ }^{\star \star *} p<0.001 v$ $S G A$.

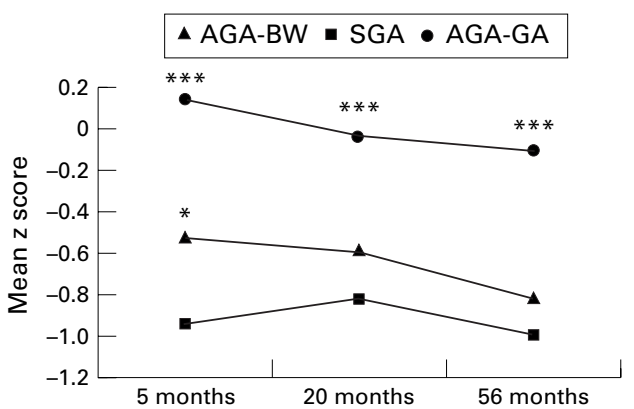

Figure 3 Group differences in head circumference at five months, 20 months, and 56 months. SGA, group of small for gestational age infants; $A G A-B W$, group of appropriate for gestational age infants matched to the $S G A$ group according to birth weight; $A G A-G A$, group of appropriate for gestational age infants matched to the $S G A$ group according to gestational age. ${ }^{\star} p<0.05,{ }^{\star \star *} p<0.001 v$ SGA.

Infants in the AGA-GA group remained heavier and longer with a larger head at five, 20, and 56 months than those in the SGA and AGA-BW groups. The SGA infants were lighter at five and 20 months than the AGA-BW infants, but caught up with the AGA-BW group with regard to weight at 56 months. The SGA infants were also shorter with a smaller head circumference than the AGA-BW infants at five months, but these differences had disappeared at 20 and 56 months.

GENERAL AND COGNITIVE DEVELOPMENT

Group differences were found in early developmental assessments (Griffiths) and later IQ and language performance (CMM, AWST, LSVTA) (table 3). AGA-GA infants overall scored higher in the Griffiths assessment at five and 20 months, the CMM, the AWST, and the LSVTA at 56 months than the other two groups. In the Griffiths scales, the AGA-BW group did not differ from the SGA group at five and 20 months. However, at 56 months, the AGA-BW had lower scores on the CMM and LSVTA than the SGA group, but had comparable scores in the AWST. The AGA-GA group scored higher in the AWST and LSVTA than the SGA group but showed similar scores in the CMM.

IQ scores were recoded to distinguish between no impairment $(>-1$ SD below the mean), mild impairment ( -1 to $-2 \mathrm{SD}$ below 
Table 3 General development at five and 20 months (Griffiths scales) and cognitive scores at 56 months (CMM, AWST, LSVTA)

\begin{tabular}{lllc}
\hline & $A G A-B W$ & $S G A$ & $A G A-G A$ \\
\hline Griffiths scales & & & \\
$\quad$ 5 months & $99.3(1.8)$ & $96.8(1.5)$ & $105.8(1.6)^{\star \star}$ \\
20 months & $95.0(1.8)$ & $96.7(1.3)$ & $102.6(0.9)^{\star \star}$ \\
CMM & $85.3(2.4)^{\star}$ & $90.0(2.0)$ & $93.7(1.7)$ \\
AWST & $84.6(2.2)$ & $85.9(1.9)$ & $93.2(2.0)^{\star \star}$ \\
LSVTA & $84.3(1.9)^{\star}$ & $90.0(2.3)$ & $95.1(1.7)^{\star}$ \\
\hline
\end{tabular}

Values are expressed as standardised mean scores (SEM) $(\mathrm{n}=115)$.

${ }^{\star} \mathrm{p}<0.05,{ }^{\star \star} \mathrm{p}<0.01,{ }^{\star \star \star} \mathrm{p}<0.001 v \mathrm{SGA}$

SGA, small for gestational age; AGA-BW, appropriate weight for gestational age matched according to birth weight; AGA-GA, appropriate weight for gestational age matched according to gestation.

Table 4 Group differences between no, minor, and severe cognitive impairment at 56 months

\begin{tabular}{|c|c|c|c|}
\hline & $A G A-B W$ & $S G A$ & $A G A-G A$ \\
\hline \multicolumn{4}{|l|}{ CMM (overall $+\dagger \dagger)$} \\
\hline No impairment & $62(53.9)$ & $71(61.7)$ & $91(79.1)^{\star}$ \\
\hline Minor impairment & $28(24.3)$ & $26(22.6)$ & $15(13.1)$ \\
\hline Severe impairment & $24(20.9)$ & $13(11.3)$ & $7(6.1)$ \\
\hline \multicolumn{4}{|l|}{ AWST } \\
\hline No impairment & $64(55.7)$ & $57(49.6)$ & $75(65.2)$ \\
\hline Minor impairment & $20(17.4)$ & $30(26.1)$ & $21(18.3)$ \\
\hline Severe impairment & $29(25.2)$ & $18(15.7)$ & $16(13.9)$ \\
\hline \multicolumn{4}{|l|}{ LSVTA (overallt†) } \\
\hline No impairment & $59(51.3)$ & $72(62.6)$ & $83(72.2)$ \\
\hline Minor impairment & $28(24.3)$ & $24(20.9)$ & $19(16.5)$ \\
\hline Severe impairment & $18(15.7)$ & $11(9.6)$ & $5(4.3)$ \\
\hline
\end{tabular}

Values are numbers with percentages in parentheses $(n=115)$. ${ }^{\star} \mathrm{p}<0.05 v$ SGA.

$+\dagger p<0.01,++\dagger p<0.001$ for overall group differences.

SGA, small for gestational age; AGA-BW, appropriate weight for gestational age matched according to birth weight; AGA-GA, appropriate weight for gestational age matched according to gestation.

the mean), and serious impairment $(<-2 \mathrm{SD}$ below the mean). Overall group differences were found for the CMM and LSVTA: the AGA-GA group had the lowest and the AGA-BW group the highest incidence of serious impairment in the CMM and LSVTA (table 4). Post hoc comparisons showed that the only significant difference between the SGA and AGA-GA group was for the CMM.

PRENATAL AND POSTNATAL COMPLICATIONS When complications (during pregnancy, at birth and neonatally), and parity and multiple birth (covariates) were accounted for, group differences in weight, length, and head circumference remained significant up to 56 months (all p < 0.001). Differences between groups in general development were only found in the Griffiths scales at five months, after adjustments for complications were made; no other group differences remained. Table 5 shows adjusted group means for general and cognitive outcomes. Complications during pregnancy were found to be a significant covariate for scores on the CMM, AWST, and LSVTA at 56 months. Neonatal complications were found to be a significant covariate for all cognitive assessments up to 56 months, whereas complications at birth had no effect on group performance at any age. Parity was a significant covariate for scores on the AWST. Post hoc comparisons showed that firstborns scored higher on the AWST than children born later in a family. Multiple birth covaried with group scores on the Griffiths scales at five months. Post hoc comparisons showed higher Griffiths scales scores for single than multiple births but no differences in cognitive scores at later ages.

\section{Discussion}

The significance of growth retardation, low birth weight, and gestation on growth and cognitive outcome of very preterm infants was investigated in this study by comparing VLBW SGA infants with AGA infants matched for either birth weight or gestation. In agreement with the results of Sung et $a l{ }^{13}$ infants in the gestation matched AGA-GA group were heavier and longer with a larger head than those in the other two groups. In their study, however, the groups did not differ in weight and length at one year, but at three years, the SGA group was lighter and shorter than the other two AGA groups. They concluded that increasing growth lags in SGA compared with AGA infants occur with increasing age. In our study, we find the opposite trend: the SGA group was lighter and shorter, and had smaller head circumference at five months than both AGA comparison groups. However, at 20 months the SGA group had caught up with the birth weight matched AGA group in length and head circumference and at 56 months in weight also. Therefore, we come to the opposite conclusion with regard to the growth of VLBW SGA infants: growth lags in SGA compared with AGA infants decrease with increasing age.

Studies on long term cognitive outcome in SGA compared with AGA infants matched according to either gestation or birth weight ${ }^{12} 13$ have found no difference in cognitive ability up to five years between SGA infants and birth weight matched AGA infants. In our study, however, we found that at 56 months, the SGA

Table 5 Adjusted means for general development at five and 20 months (Griffiths scales) and cognitive development at 56 months (CMM, AWST, LSVTA) controlling for complications (pregnancy, at birth, and neonatally), parity and multiple birth

\begin{tabular}{|c|c|c|c|c|c|c|c|c|c|}
\hline & \multicolumn{4}{|l|}{ Groups } & \multicolumn{5}{|c|}{ Covariates (F scores) } \\
\hline & \multirow{2}{*}{$\begin{array}{l}A G A-B W \\
(n=115)\end{array}$} & \multirow{2}{*}{$\begin{array}{l}S G A \\
(n=115)\end{array}$} & \multirow{2}{*}{$\begin{array}{l}A G A-G A \\
(n=115)\end{array}$} & \multirow{2}{*}{$\begin{array}{l}F \\
\text { (group) }\end{array}$} & \multicolumn{3}{|c|}{ Complications } & \multirow[b]{2}{*}{ Parity } & \multirow{2}{*}{$\begin{array}{l}\text { Multiple } \\
\text { birth }\end{array}$} \\
\hline & & & & & Pregnancy & Birth & Neonatally & & \\
\hline \multicolumn{10}{|c|}{ Griffiths scales } \\
\hline 5 months & $100.9(1.7)$ & $96.8(1.6)$ & $104.1(1.7)$ & $4.74^{\star}$ & 0.02 & 0.18 & $10.17^{\star \star}$ & 0.46 & $5.1^{\star}$ \\
\hline 20 months & $96.5(1.4)$ & $97.2(1.4)$ & $100.4(1.5)$ & 1.80 & 2.30 & 0.20 & $18.72^{\star \star \star}$ & 0.59 & 0.67 \\
\hline CMM & $86.3(2.1)$ & $90.3(2.0)$ & $90.0(2.1)$ & 1.19 & $5.90^{\star}$ & 0.02 & $19.58^{\star \star \star}$ & 1.36 & 1.13 \\
\hline AWST & $85.7(2.0)$ & $87.1(2.0)$ & $88.7(2.0)$ & 0.51 & $7.98^{\star \star}$ & 0.17 & $19.30^{\star \star \star}$ & $13.55^{\star \star \star}$ & 0.23 \\
\hline LSVTA & $86.5(2.0)$ & $90.8(1.9)$ & $91.6(2.0)$ & 1.81 & $9.40^{\star \star}$ & 1.30 & $21.51^{\star \star \star}$ & 2.94 & 0.09 \\
\hline
\end{tabular}

Values are expressed as adjusted standardised mean scores (SEM).

${ }^{\star} \mathrm{p}<0.05,{ }^{\star \star} \mathrm{p}<0.01,{ }^{\star \star \star} \mathrm{p}<0.001$. 
infants are actually performing better in IQ and language related tests than the birthweight matched infants. In addition, we found a tendency for the AGA-BW group to display more severe cognitive deficits than the other two groups; however, the difference from the SGA group did not reach statistical significance. The AGA-BW group in the study of Sung et $a l^{13}$ also displayed the most neonatal complications and displayed the lowest cognitive performance of all three groups. The fact that the difference between the AGA-BW and the SGA group did not reach significance in that study may have been due to the small sample size $(n=27)$ per group. Our findings support the tentative conclusion of Sung et al that "extreme immaturity (short gestation) at the time of delivery has significant effects on cognitive development that surpass the effects of IUGR".

Several studies that have shown long term cognitive differences between SGA and AGA infants have neglected to control for neonatal complications and sociodemographic factors. $^{5613}$ In this study, the SGA and AGA groups were highly comparable with regard to sociodemographic factors. Thus differences in growth and general and cognitive development cannot be accounted for by differences in social factors. In contrast, the three groups differed in complications, with the AGA-BW group experiencing the most neonatal complications.

We found that even when the influence of prenatal and especially postnatal complications was controlled for, the group differences in growth remained significant up to five years; however, the differences in cognitive outcome disappeared after five months. This indicates that neonatal complications are more closely associated with early gestation, and have a larger impact on long term cognitive outcome than on long term growth. Neonatal and pregnancy complications are the major factors explaining individual differences in cognitive scores in VLBW children. ${ }^{47}$

This study unfortunately has no assessments of abnormal fetal heart rate, abnormal umbilical artery waveforms, or fetal cerebral arterial Doppler assessment. ${ }^{28-30}$ However, it is not yet clear whether cerebral redistribution (brain sparing) is a healthy adaptation to stress or a warning sign for long term developmental problems. Furthermore, maternal or paternal smoking did not differ between groups.

Higher parity was linked to lower language scores at 56 months (also reported in preterm infants by Largo et $\left.a^{\beta 1}\right)$. Once complications and parity were controlled for, all differences in language disappeared. Further studies may clarify the role of parity on the language development of VLBW SGA infants-that is, whether VLBW infants born later in a family are less stimulated in their language development. ${ }^{32}$ In conclusion, our findings suggest that, for VLBW infants, complications during pregnancy and especially neonatally have a larger detrimental effect on long term cognitive development than whether they are born SGA or AGA.

\section{Key message}

Differences in growth between SGA and AGA VLBW infants were found to persist up to 5 years of age, independently of prenatal and postnatal complications. In contrast, complications during pregnancy and the neonatal period had a larger effect on infant cognitive development than size for gestation (SGA $v \mathrm{AGA}$ ).

The research was supported by the Bundesministerium für Forschung und Technologie (Federal Government of Germany, Ministry of Science and Technology) programme grants PKE 4 and JUG 14 (FKZs 0706224,0706564 , and 01EP9504) to K R, $\mathrm{D} W$ and B O. Thanks are due to the 16 special care baby units in South Bavaria, the paediatricians, psychologists, and psychometric assistants who carried out the assess
the parents and children who participated.

1 Ericson A, Källen B. Very low birthweight boys at the age of 19. Arch Dis Child Fetal Neonatal Ed 1998;78:F171-4

19. Arch Dis Child Fetal Neonatal Ed 1998;78:F171-4.
Kitchen WH, Doyle LW, Ford GW, Callanan C. Very low birth weight and growth to age 8 years. I. Weight and height. American fournal of Diseases of Children 1992;146:40-5

3 Riegel K, Ohrt B, Wolke D, Österlund K. Die Entwicklung gefährdet geborener Kinder bis zum fünften Lebensjahr. (The development of at-risk children until the fifth year of life. The Arvo Ylppö longitudinal study in South Bavaria and South Finland). Stuttgart: Ferdinand Enke Verlag, 1995.

4 Wolke D. Psychological development of prematurely born children. Arch Dis Child 1998;78:567-70.

5 Hutton JL, Pharoah POD, Cooke RWI, Stevenson RC. Differential effects of preterm birth and small for gestational age on cognitive and motor development. Arch Dis Child 1997;76:F75-81.

6 Smedler A C, Faxelius G, Bremme K, Lagerstrom M. Psychological development in children born with very low birth weight after severe intrauterine growth retardation: a 10-year follow-up study. Acta Paediatr 1992;81:197-203.

7 Frisancho AR, Fields S, Smith SL. Small for gestational age associated with short stature during adolescence. American fournal of Human Biology 1994;6:305-9.

8 Paz I, Gale R, Laor A, Danon YL, Stevenson DK, Seidman DS. The cognitive outcome of full-term small for gestational age infants at late adolescence. Obstet Gynecol 1995;85:452-5.

9 Pryor J, Silva PA, Brooke M. Growth, development and behaviour in adolescents born small-for-gestational-age. $\mathcal{F}$ Paediatr Child Health 1995;31:403-7.

10 Veelken N, Stollhoff K, Claussen M. Development and perinatal risk factors of very low-birthweight infants. Small versus appropriate for gestational age. Neuropediatrics 1992;23:102-7.

11 Spinillo A, Capuzzo E, Piazzi G, Baltaro F, Stronati M, Ometto A. Significance of low birthweight for gestational age among very preterm infants. Br $\mathcal{F}$ Obstet Gynaecol 1997;104:668-73.

12 McCarton CM, Wallace IF, Divon M, Vaughan HG. Cognitive and neurologic development of the premature small for gestational age infant through age 6: comparison by birth weight and gestational age. Pediatrics 1996;98:116778 .

13 Sung I-K, Vohr B, Oh, W. Growth and neurodevelopmental outcome of very low birth weight infants with intrauterine growth retardation: comparison with control subjects matched by birth weight and gestational age. $\mathcal{F}$ Pediatr 1993;123:618-24.

14 Allen M. Developmental outcome and follow up of the small for gestational age infant. Semin Perinatol 1984;8:123-56.

15 Wolke D, Meyer R, Ohrt B, Riegel K. The incidence of sleeping problems in preterm and fullterm infants
discharged from special neonatal care units: an epidemiological longitudinal study. $\mathcal{f}$ Child Psychol Psychiatry 1995;36:203-23.

16 Wolke D, Söhne B, Ohrt B, Riegel K, Österlund, K. An epidemiological study of sleeping problems and feeding experiences of preterm and fullterm children in South Finnland: comparison to a South German population sample. F Pediatr 1998;133:224-31.

7 Dubowitz L, Dubowitz V. Clinical assessment of gestational age in the newborn infant. London: Cow \& Gate, 1979.

18 Wolke D, Ratschinski G, Ohrt B. The cognitive outcome of very preterm infants may be poorer than often reported: an empirical investigation of how methodological issues make a big difference. Eur $\mathcal{F}$ Pediatr 1994;153:906-15.

19 Wolke D, Söhne B, Ohrt B, Riegel K. Follow-up of preterm children: important to document dropouts. Lancet 1995;345:447.

20 Casaer P, Eggermont E. Neonatal clinical neurological assessment. In: Harel S, Nicholas NJ, eds. The at-risk infant: psycho/socio/medical aspects. Baltimore: Brookes,
1985:197-220. 
21 Bauer A. Ein Verfahren zur Messung des für das Bildungsverhalten relevanten Status (BRSS). Frankfurt: Deutsches Institut für Internationale Pädagogische Forschung, 1988.

22 Brandt I. Griffiths Entwicklungsskalen (GES zur Beurteilung der Entwicklung in den ersten beiden Lebensjahren). Weinheim: Beltz, 1983.

23 Burgermeister BB, Blum LH, Lorge I. The Columbia mental maturity scale manual. Yonkers-on-Hudson, NY: World, 1954.

24 Bondy C, Cohen R, Eggert D, Lüer G. Testbatterie für geistig behinderte Kinder. TBGB. Manual. Weinheim: Beltz, 1975.

25 Kiese C, Kozielski P. Aktiver Wortschatztest für drei-bis sechsjährige Kinder. AWST 3-6. Weinheim: Beltz, 1979.

26 Wettstein P. LSVT: Logopädischer Sprachverständnis-Test. Zürich: Heilpädagogisches Seminar, 1983.

27 Wolke D, Meyer R. Cognitive status, language attainment and pre-reading skills of 6 year-old very preterm children
and their peers: the Bavarian longitudinal study. Dev Med Child Neurol 1999;41:94-109.
28 Scherjon SA, Oosting H, Smolders-DeHaas H, Zondervan HA, Kok JH. Neurodevelopmental outcome at three years of age after fetal brain-sparing. Early Hum Dev 1998;52:67-79

29 Scherjon SA, Smolders-DeHaas H, Kok JH, Zondervan HA. The "brain-sparing" effect: antenatal cerebral Doppler findings in relation to neurologic outcome in very preterm infants. Am f Obstet Gynecol 1993;169:169-75.

30 Soothill PW, Ajayi RA, Nicolaides KN. Fetal biochemistry in growth retardation. Early Hum Dev 1992;29:91-7.

31 Largo RH, Molinari L, Comenale PL, Weber M, Duc G. Language development of term and preterm children during the first five years of life. Dev Med Child Neurol 1986;28:333-50.

32 Wolke D. Language problems in neonatal at risk children: towards an understanding of developmental mechanisms [invited commentary]. Acta Paediatr 1999;88:488-90. 